tions may occur with exercise or other stresses, but the evidence for this in man could be obtained only directly from the cerebrospinal fluid, which is clearly not practical. In future it should be possible to investigate central opioid activity when there are more specific antagonist drugs, rather than naloxone or naltrexone, which have a preferential affinity for $\mu$ receptors and an analgesic function. Another alternative is to use positron emission tomography with an opiate labelled ligand. ${ }^{5}$

Finally, I also doubt whether it is significant that in the past six years all of the runners who have collapsed at the end of the Great North Run have been men-the entrants to such runs are predominantly men, in the ratio of about 10 to 1 .

David Veale

Academic Department of Psychiatry,

Royal Free Hospital School of Medicine,

London NW3 2QG

1 Veale DMW de C. Exercise and mental health. Acta Psychiatr Scand (in press)

2 Fraioli F, Moretti C, Paolucci D, Alicoccio E, Creccenzi F. Physical exercise stimulates marked concomitant release of $\beta$-endorphin and ACTH in man. Experientia 1980;36:987-9.

3 Grossman A, Bouloux P, Price P, et al. The role of opioid peptides in the hormonal responses to acute exercises in man. peptides in the hormona
Clin Sci 1984;67:483-91.

4 Nakao K, Nakai Y, Oki S, Matsubara S, Konishi T, Imura H Immunoreactive $\beta$-endorphin in human cerebrospinal fluid. f Clin Endocrinol Metab 1980;50:230-3.

5 Jones AKP, Luthra SK, Pike VW, Herold S, Brady F. New labelled ligand for in-vivo studies of opioid physiology. Lance 1985;ii:665-6.

\section{Corticosteroids and bone mass in asthma}

SIR,-Dr G J Addis (7 March, p 644) is concerned that we should respond to Dr G K Crompton's thoughtful criticism (10 January, p 123) of our paper (6 December 1986, p 1463).

In his letter Dr Crompton drew attention to the difficulties of obtaining detailed information retrospectively from hospital records and expressed the belief that some of the patients studied who were under his own care may have received additional courses of systemic corticosteroids that were not recorded. As Dr Crompton is a close colleague working in a neighbouring unit that was collaborating in our study our initial response was to ask him to make his own independent assessment of the corticosteroid intake of the patients concerned. Subsequently, however, $\mathrm{Dr}$ Addis's letter has prompted us to review ourselves, as carefully as possible, the case records of those patients in group 3 who were classified as having received only inhaled steroids, with or without short booster courses of systemic corticosteroids, and to supplement this information with information obtained from the patients themselves and, in some cases, their general practitioners.

Twenty out of 22 case records were traced, and four discrepancies have been ascertained. One man .(aged 21) who was classified as having received no oral corticosteroids was found to have received intermittent systemic corticosteroids for several years before total body calcium was measured, although not in the two years immediately before bone mass was estimated. Exclusion of this patient from the group leaves a total of 21 patients $(10$ men and 11 women), with a mean (SD) age of $57 \cdot 2$ $(10 \cdot 2)$ years. Compared with the 40 normal controls, mean total body calcium was still reduced by $8.4 \%(p<0.001)$. Three discrepancies were found in the calculation of the number of booster courses of oral corticosteroids. Two men, previously classified as not having received any, had in fact received two and one 10 day booster courses of steroids. Another man thought to have had only one booster course seems to have had at least five, and five of the patients treated with both inhaled steroids and booster courses had in fact taken higher doses of inhalation steroids for short periods. Clearly, it is impossible in a retrospective study of this kind to determine the relative importance of the inhaled corticosteroids and the intermittent short booster courses of systemic steroids in the associated reduction in total bone mass, but a recent study of bone metabolism during methylprednisolone pulse treatment in rheumatoid arthritis failed to show a significant effect.

Dr Crompton also questions the possibility that the differences in total body calcium between those patients who had never received corticosteroid treatment (group 4) and those treated with inhaled corticosteroids with or without booster courses of systemic steroids (group 3) could partly be explained by their differences in mean age. As stated in the paper, we do not believe this to be the case as previous studies of total body calcium in normal subjects have failed to show a relation between bone mass and age in men or premenopausal women. ${ }^{2}$ Demographic details of normal subjects and the derivation of the normal range for total body calcium have been published, ${ }^{3}$ and details were therefore not included in this paper.

While Dr Crompton may well be correct in believing that patients with asthma apparently controlled with inhaled corticosteroids alone require short booster courses of systemic corticosteroids more often than is always apparent, our data do suggest that patients treated in this way may suffer some reduction in total bone mass. The only way to be certain whether it is the inhaled corticosteroids, the intermittent booster courses of systemic corticosteroids, or the combination of both that is responsible is to undertake prospective studies.

D M REID

J J NICOLL

P TOTHILI

Rheumatic Diseases Unit,

Northern General Hospital,

Northern General Hosp
Edinburgh EH5 2DQ

1 Bijlsma JWJ, Duursma SA, Huber-Bruning O. Bone metabolism during methyl prednisolone pulse therapy in rheumatoid arthritis. Ann Rheum Dis 1986;45:757-60.

2 Cohn SH, Vaswani A, Zanzi I, Aloia JF, Roginksy MS, Ellis KJ. Changes in body chemical composition with age measured by total body neutron activation. Metabolism 1976;25:85-95.

3 Kennedy NSJ, Eastell R, Ferrington CM, et al. Total body neutron activation analysis of calcium: calibration and normalisation. Phys Med Biol 1982;27:697-707.

\section{A forgotten factor in pelvic inflammatory disease: infection in the male partner}

SIR,-While we agree with Dr Martha Jacob and colleagues (4 April, p 869) that the sexual contacts of women with pelvic inflammatory disease should be traced and treated, we believe that this conclusion could have been based on better clinical and microbiological evidence.

Firstly, we know that the diagnosis of what seems to be pelvic inflammatory disease on clinical grounds is often not supported by laparoscopic findings. Dr Jacob and colleagues diagnosed pelvic inflammatory disease on the basis of lower abdominal pain, adnexal tenderness, and positive cervical excitation. In a current study of our own, in which 50 women have been seen with similar signs and symptoms, only $14(28 \%)$ have been found to have pelvic inflammatory disease by laparoscopy. Moreover, of 14 women who were found to have chlamydias in the cervix, only six (43\%) had laparoscopic evidence of pelvic inflammatory disease.

The absence of laparoscopic evidence in most cases in the study by Dr Jacob and colleagues therefore leaves the proportion of true cases of pelvic inflammatory disease open to question and means that their study cannot be compared with others in which this examination was done routinely. Furthermore, we wonder about the relevance of the chlamydial investigations performed by Dr Jacob and coworkers. As the relation of Chlamydia trachomatis in the cervices of their patients to pelvic inflammatory disease is unknown and as they do not comment on the relation between chlamydial infections in the women and those in the male partners the value of such tests is not clear. What is clear is that many male contacts had non-gonococcal urethritis, often without symptoms. Of course, this is probably true of the male partners of many groups of women with infections of the genital tract, and to advise that the sexual contacts of women with pelvic inflammatory disease should be sought and treated goes without saying.

C M STACEY

D TAYLOR-ROBINSON P E MUNDAY

Praed Street Clinic,

St Mary's Hospital

London W2 INY

Social class, non-employment, and chronic illness

SIR,-Ms Sara Arber (25 April, p 1069) obtained the data on levels of ill health from the General Household Survey for 1981 and 1982, which, as she states, is based both on people's perceptions of their ill health and on their willingness and ability to report it to interviewers who are presumably non-medical.

Surely it must be questioned whether such subjective judgments can form the basis for a reliable estimate of the prevalence of ill health in any section of the community. Furthermore, unemployment is a demoralising state that would probably enhance any negative feelings an individual has about his or her health and thus give rise to further bias.

Mortality ratios are another matter. But I would suggest that it is better to concentrate on and try to evaluate the extent of the known and at present accepted causes of ill health-inherited factors, bad housing, smoking, alcohol abuse, inappropriate diet, and lack of exercise-and the relation of these to ill health. Surveys directed to such matters are more likely to throw light on the prevalence and causation of ill health and might in the longer term help point the way to how these factors can best be influenced to the benefit of the health of the community.

MichaEl J SCOTT

Dundonald

Ayrshire KA2 9EY

AUTHOR's REPLY,-The General Household Survey data for 1981-2 show that unemployed men reported $43 \%$ more limiting longstanding illness than all men and employed men reported $18 \%$ less, after standardising for differences in age. Dr Scott argues that these findings can be dismissed because they are based on "subjective judgments from individuals." This exemplifies the well known ploy of trying to discredit undesirable findings by suggesting that they are a methodological artefact.

There is substantial research evidence that an individual's general estimate of his or her own health, as measured by the General Household Survey question on longstanding illness, correlates well with the incidence of a wide range of health symptoms. The recent Health and Lifestyle Survey, conducted by a research team at Cambridge, provides further evidence that subjective judgments are valid measures of health status ${ }^{1}(M$ 